\title{
HEAT TRANSFER ANALYSIS OF NON-NEWTONIAN NATURAL CONVECTIVE FLUID FLOW USING HOMOTOPY PERTURBATION AND DAFTARDAR-GEJIJI \& JAFARI METHODS
}

\author{
Olurotimi Adeleye ${ }^{1}$, Ahmed Yinusa ${ }^{2}$ \\ ${ }^{l}$ Department of Systems Engineering, University of Lagos \\ Akoka, Lagos, Nigeria \\ ${ }^{2}$ Department of Mechanical Engineering, University of Lagos \\ Akoka, Lagos, Nigeria \\ rotimiadeleye1711@gmail.com,mynotebook2010@yahoo.com
}

Received: 9 January 2019; Accepted: 16 June 2019

\begin{abstract}
In this paper, the analytical solution of natural convective heat transfer of a nonNewtonian fluid flow between two vertical infinite plates using the Homotopy Perturbation Method (HPM) and Daftardar-Gejiji \& Jafari Method (DJM) is presented. The heat transfer problem of natural convection is observed in many engineering fields including geothermal systems, heat exchangers, petroleum reservoirs, nuclear waste reserves, etc. The problem which is modelled as fully coupled nonlinear ordinary differential equations requires special analytical techniques for its solution. The solutions are obtained using an exact analytical method: the Homotopy Perturbation Method (HPM) and a semi-analytical method: the Daftardar-Gejiji \& Jafari Method (DJM). These solutions are compared with solutions obtained from the Runge-Kutta numerical method. The results are in good agreement with the numerical solutions. The effects of the Eckert number, Prandtl number and the nonNewtonian fluid viscosity parameter on the non-dimensional temperature and velocity of the fluid are investigated. The results obtained from the analytical method show that the method can be applied to predict excellent results of the problem and can be used for parametric studies of the problem. From the results, it is shown that when the Prandtl number and the Eckert number are increased, there is an increase in both temperature and fluid flow velocity.
\end{abstract}

MSC 2010: $80 A 20$

Keywords: non-Newtonian fluid, natural convection, vertically infinite plates, Daftardar-Gejiji \& Jafari Method (DJM), Homotopy Perturbation Method (HPM)

\section{Introduction}

The problem of heat transfer in non-Newtonian fluids flowing between two vertical infinite parallel plates in free convection has been observed in many engi- 
neering applications including petroleum reservoirs, heat exchangers, geothermal systems, nuclear waste reserves. etc. This problem is of great concern and has attracted a lot of interest and study in the past few decades. Quite a number of studies have been carried out on problems related to it. The natural convective heat transfer of non-Newtonian fluid in porous media has been studied [1]. The heat transfer of non-Newtonian fluid in various applications has been studied by applying numerical methods and analytical methods [2-8]. Darvishi et al. [9] investigated the effects of heat losses in porous fin in natural convection and in the radiation process.

The rheological properties of non-Newtonian fluids are complicated, and it is difficult to put them all in one mathematical model. One of the mathematical models used for such fluids is the "third grade fluid" model. This model is most often used for viscoelastic fluids $[10,11]$ and it is represented by nonlinear differential equations. Numerical methods were used to obtain solutions for some of them [12] and some by perturbation methods [13]. The major obstacles for numerical methods in obtaining an appropriate solution are stability and convergence, while the limitation of method of perturbation is the occurrence of a small parameter. Due to this occurrence, a number of analytical methods have been developed including the Variation Iteration Method (VIM) [14], the Differential Transform Method (DTM) [15], the Homotopy Analysis Method (HAM) [16] and the Adomian Decomposition Method (ADM) [17]. One of the new analytical methods that was developed to overcome the shortcoming of the perturbation method is the Homotopy Perturbation Method.

The Homotopy Perturbation Method (HPM) is a powerful analytical method for solving nonlinear differential equations. It is an exact analytical tool that does not require any approximation. Various studies have been done with the Homotopy Perturbation Method (HPM) such as use of the Homotopy Perturbation Method for the analysis of heat transfer in longitudinal fins [18], the use of the Homotopy Perturbation Method (HPM) and collocation method (CM) for analysis of thermal performances of porous fin with temperature-dependent heat generation [19] and the Homotopy perturbation method for a three dimensional problem of condensation film on an inclined rotating disk [20]. Another method used in this study for solving the problem of heat transfer of a non-Newtonian natural convective fluid flow between two vertical infinite flat plates is a new iterative method called the Daftardar-Jafari method (DJM). It was developed in 2006 and has been shown to be very efficient in solving nonlinear problems [21-23]. The Daftardar-Jafari method was developed to improve upon the Adomian Decomposition Method (ADM). The method converges its solution to the exact solution after successive approximations [21-23]. Some major advantages of this method are that it comes with its associated error control procedures and is used to solve nonlinear differential equations of integral and fractional order.

Hence, the aim of this study is to provide solutions to the problem of heat transfer of non-Newtonian natural convective fluid between two vertically infinite plates by using the Homotopy Perturbation Method (HPM) and the Daftardar-Gejiji $\&$ Jafari method (DJM). These solutions were compared with numerical method 
and the effects of the Eckert number, the Prandtl number and the non-Newtonian fluid viscosity parameter on temperature and velocity were investigated.

\section{Description of the problem}

The equations of the heat transfer of the non-Newtonian fluid flow between vertical plates [24] are obtained from the basic law of conservation of mass, momentum and energy for an incompressible fluid and are given respectively by:

$$
\begin{gathered}
\nabla \cdot \mathbf{V}=0 \\
\boldsymbol{\rho} \frac{D \mathbf{V}}{D t}=\mathbf{f b}+\operatorname{div}(\tau) \\
\boldsymbol{\rho c}_{\mathbf{p}} \frac{D \mathbf{T}}{D t}=\boldsymbol{K} \nabla^{2} \mathbf{T}+\tau \cdot \mathbf{L}
\end{gathered}
$$

where $\boldsymbol{\tau}, \boldsymbol{\rho}, \mathbf{f b}, \mathbf{T}, \mathbf{K}, \mathbf{V}, \mathbf{c}_{\mathbf{p}}$, and $\mathbf{L}$ represent the stress tensor, constant fluid density, body force, temperature field, thermal conductivity, velocity field and specific heat at constant pressure and the gradient of $\mathbf{V}$ respectively. The constitutive relation, depicting the non-Newtonian fluid is

$$
\tau=-p I+\mu \mathbf{A}_{1}+\alpha_{1} \mathbf{A}_{2}+\alpha_{2} \mathbf{A}_{1}^{2}+\beta_{1} \mathbf{A}_{3}+\beta_{2}\left(\mathbf{A}_{1} \mathbf{A}_{2}+\mathbf{A}_{2} \mathbf{A}_{1}\right)+\beta_{3}\left(\operatorname{tr} \mathbf{A}_{2}\right) \mathbf{A}_{1}
$$

where $p$ denotes pressure, $\mu$ is coefficient of viscosity and $\alpha_{1}, \alpha_{2}, \beta_{1}, \beta_{2}, \beta_{3}$ are the material constants. $\mathbf{A}_{1}, \mathbf{A}_{2}, \mathbf{A}_{3}$ are Erickson tensors, and are defined by

$$
\begin{aligned}
& \mathbf{A}_{1}=\mathbf{L}+\mathbf{L}^{T} \\
& \mathbf{A}_{n}=\frac{d \mathbf{A}_{n-1}}{d t}+\mathbf{A}_{n-1}(\operatorname{grad} \mathbf{V})+(\operatorname{grad} \mathbf{V})^{T} \mathbf{A}_{n-1}, n \geq 1
\end{aligned}
$$

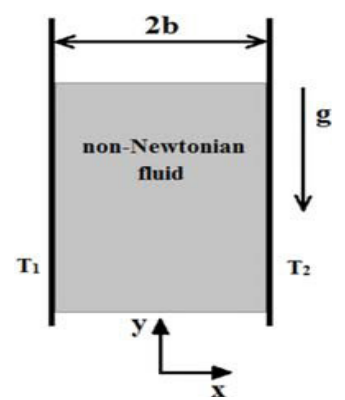

Fig. 1. Schematic diagram of the two vertically infinite parallel flat plates

The item shown in Figure 1 consists of two vertical parallel plates. If a steady flow of the incompressible non-Newtonian fluid between two infinite parallel 
plates of distance $2 b$ apart is considered, with the walls at $x=+b$ and $x=-b$ and a temperature $\varphi_{2}$ and $\varphi_{1}$ respectively where $\varphi_{1}>\varphi_{2}$. As a result of temperature difference, the fluid at $x=+b$ will fall and the fluid at $x=-b$ will rise.

A one-dimensional temperature and velocity field of the form in Eq. (7) is required.

$$
\mathbf{V}=[u(\xi), 0,0], \quad \mathbf{T}=T(\xi)
$$

Following Rajagopal [25], the variables are defined as

$$
U=\frac{u}{U_{0}}, \zeta=\frac{x}{b}, \varphi=\frac{T-T_{m}}{T_{1}-T_{2}},
$$

And equations (2) and (3) are reduced to a pair of coupled nonlinear ordinary differential equations

$$
\begin{gathered}
\frac{d^{2} U}{d \zeta^{2}}+6 \delta\left(\frac{d U}{d \zeta}\right)^{2} \frac{d^{2} U}{d \zeta^{2}}+\varphi=0 \\
\frac{d^{2} \varphi}{d \zeta^{2}}+\operatorname{Ec} \operatorname{Pr}\left(\frac{d U}{d \zeta}\right)^{2} \frac{d^{2} U}{d \zeta^{2}}+2 \delta \operatorname{Ec} \operatorname{Pr}\left(\frac{d U}{d \zeta}\right)^{4}=0
\end{gathered}
$$

where the Eckert number (Ec), the Prandtl number (Pr) and a dimensionless quantity; the non-Newtonian viscosity $(\delta)$ have the form

$$
\mathrm{Ec}=\frac{U_{0}^{2}}{c\left(T_{1}-T_{2}\right)}, \quad \operatorname{Pr}=\frac{\mu c}{k}, \quad \delta=\frac{6\left(\beta_{2}+\beta_{3}\right) U_{0}^{2}}{\mu b^{2}}
$$

And the specific heat of the fluid is given as $c$.

The boundary conditions are

$$
U(-1)=0, \varphi(-1)=+\frac{1}{2}, U(1)=0, \varphi(1)=-\frac{1}{2}
$$

\section{Method of solution: Homotopy Perturbation Method (HPM)}

Consider the given function

$$
A(u)-f(r)=0
$$

With given boundary conditions as

$$
B\left(u, \frac{\partial u}{\partial n}\right)=0
$$


Where $A(u)$ is expressed as

$$
A(u)=L(u)-N(u)
$$

The Homotopy Perturbation procedure is shown as:

$$
\begin{array}{r}
H(v, p)=L(v)-L\left(u_{0}\right)+p \cdot L\left(u_{0}\right)+p[N(v)-f(r)]=0 \\
\text { or } \quad H(v, p)=(1-p)\left[L(v)-L\left(u_{0}\right)\right]+p[A(v)-f(r)]=0
\end{array}
$$

The solution is represented by

$$
\begin{gathered}
U=u_{0}+p u_{1}+p^{2} u_{2}+p^{3} u_{3}+p^{4} u_{4}+p^{5} u_{5} \\
\varphi=\phi_{0}+p \phi_{1}+p^{2} \phi_{2}+p^{3} \phi_{3}+p^{4} \phi_{4}+p^{5} \phi_{5}
\end{gathered}
$$

The homotopy perturbation solution is obtained as follows

$$
\begin{gathered}
H(U, p)=(1-p)\left[\frac{d^{2} U}{d \zeta^{2}}\right]+p\left[6 \delta\left(\frac{d U}{d \zeta}\right)^{2} \frac{d^{2} U}{d \zeta^{2}}+\varphi\right]=0 \\
H(\varphi, p)=(1-p)\left[\frac{d^{2} \varphi}{d \zeta^{2}}\right]+p\left[\operatorname{Ec} \operatorname{Pr}\left(\frac{d U}{d \zeta}\right)^{2} \frac{d^{2} U}{d \zeta^{2}}+2 \delta \operatorname{Ec} \operatorname{Pr}\left(\frac{d U}{d \zeta}\right)^{4}\right]=0
\end{gathered}
$$

A solution of Eqs. (21) and (22) can then be obtained in the form

$$
\begin{aligned}
& \mathrm{U}(\zeta)=u_{0}(\zeta)+p u_{1}(\zeta)+p^{2} u_{2}(\zeta)+p^{3} u_{3}(\zeta)+p^{4} u_{4}(\zeta)+p^{5} u_{5}(\zeta)+\ldots \\
& \varphi(\zeta)=\phi_{0}(\zeta)+p \phi_{1}(\zeta)+p^{2} \phi_{2}(\zeta)+p^{3} \phi_{3}(\zeta)+p^{4} \phi_{4}(\zeta)+p^{5} \phi_{5}(\zeta)+\ldots
\end{aligned}
$$

Substituting Eqs. (18) and (19) into (20) and (21), yields

$$
\begin{aligned}
& (1-p)\left[\frac{d^{2}\left(u_{0}+p u_{1}+p^{2} u_{2}+p^{3} u_{3}+p^{4} u_{4}+p^{5} u_{5}\right)}{d \zeta^{2}}\right]+ \\
& p\left[\begin{array}{l}
6 \delta\left(\frac{d\left(u_{0}+p u_{1}+p^{2} u_{2}+p^{3} u_{3}+p^{4} u_{4}+p^{5} u_{5}\right)}{d \zeta}\right)^{2} \\
\phi_{0}+p \phi_{1}+p^{2} \phi_{2}+p^{3} \phi_{3}+p^{4} \phi_{4}+p^{5} \phi_{5}
\end{array}\right]=0
\end{aligned}
$$




$$
\begin{aligned}
& (1-p)\left[\frac{d^{2}\left(\phi_{0}+p \phi_{1}+p^{2} \phi_{2}+p^{3} \phi_{3}+p^{4} \phi_{4}+p^{5} \phi_{5}\right)}{d \zeta^{2}}\right]+ \\
& p\left[\begin{array}{l}
\operatorname{EcPr}\left(\frac{d\left(u_{0}+p u_{1}+p^{2} u_{2}+p^{3} u_{3}+p^{4} u_{4}+p^{5} u_{5}\right)}{d \zeta}\right)^{2} \frac{d^{2}\left(u_{0}+p u_{1}+p^{2} u_{2}+p^{3} u_{3}+p^{4} u_{4}+p^{5} u_{5}\right)}{d \zeta^{2}}+ \\
+2 \delta \operatorname{EcPr}\left(\frac{d\left(u_{0}+p u_{1}+p^{2} u_{2}+p^{3} u_{3}+p^{4} u_{4}+p^{5} u_{5}\right)}{d \zeta}\right)^{4}
\end{array}\right]=0
\end{aligned}
$$

Equating the coefficients of $p^{0}, p^{1}, p^{2}, p^{3}, p^{4}, p^{5}$ in equations (24) and (25) to zero, we obtain equations with respect to $u_{0}, u_{1}, u_{2}, u_{3}, u_{4}, u_{5}$, and $\phi_{0}, \phi_{1}, \phi_{2}$, $\phi_{3}, \phi_{4}, \phi_{5}$.

Solving the equations for coefficients of $p^{0}$ in Eqs. (24) and (25) using boundary condition (12)

$$
\therefore u_{0}=0 \quad \phi_{0}=-\frac{1}{2} \zeta
$$

Using Eq. (26) and boundary condition (12), solving the equations for coefficients of $p^{1}$ in Eqs. (24) and (25), we obtained

$$
u_{1}=\frac{1}{12} \zeta\left(\zeta^{2}-1\right), \phi_{1}=0
$$

Using Eq. (27) and boundary condition (12), solving the equations for coefficients of $p^{2}$ in Eqs. (24) and (25), we obtained

$$
u_{2}=0, \phi_{2}=0
$$

Using Eq. (28) and boundary condition (12), solving the equations for coefficients of $p^{3}$ in Eqs. (24) and (25), we obtained

$$
u_{3}=0, \phi_{3}=0
$$

Using Eq. (29) and boundary condition (12), solving the equations for coefficients of $p^{4}$ in Eqs. (24) and (25), we obtained

$$
\begin{aligned}
& u_{4}=-\frac{\delta}{10080}\left[45 \zeta^{7}-63 \zeta^{5}+35 \zeta^{3}-17 \zeta\right] \\
& \phi_{4}=-\frac{\operatorname{EcPr}}{60480}\left[45 \zeta^{7}-63 \zeta^{5}+35 \zeta^{3}-17 \zeta\right]
\end{aligned}
$$


Using Eqs. (30) and (31) and boundary condition (12), solving the equations for coefficients of $p^{5}$ in Eqs. (24) and (25), we obtained

$$
\begin{gathered}
u_{5}=\frac{\operatorname{Ec} \operatorname{Pr}}{1451520}\left[15 \zeta^{9}-36 \zeta^{7}+42 \zeta^{5}-68 \zeta^{3}+47 \zeta\right] \\
\phi_{5}=-\frac{\delta \operatorname{Ec} \operatorname{Pr}}{725760}\left[63 \zeta^{10}-135 \zeta^{8}+126 \delta^{6}-70 \delta^{4}+35 \delta^{2}-19\right]
\end{gathered}
$$

Hence $U(\zeta)$ and $\varphi(\zeta)$ are defined as:

$$
\begin{gathered}
U(\zeta)=\frac{1}{12}\left(-\zeta+\zeta^{3}\right)+\frac{1}{10080}\left(17 \delta \zeta-35 \delta \zeta^{3}+63 \delta \zeta^{5}-45 \delta \zeta^{7}\right) \\
+\frac{1}{1451520}\left(47 \mathrm{Ec} \operatorname{Pr} \zeta-68 \mathrm{Ec} \operatorname{Pr} \zeta^{3}+42 \mathrm{Ec} \operatorname{Pr} \zeta^{5}-36 \mathrm{Ec} \operatorname{Pr} \zeta^{7}+15 \mathrm{Ec} \operatorname{Pr} \zeta^{9}\right) \\
\varphi(\zeta)=-\frac{\zeta}{2}+\frac{1}{60480}\left(17 \mathrm{Ec} \operatorname{Pr} \zeta-35 \mathrm{Ec} \operatorname{Pr} \zeta^{3}+63 \mathrm{Ec} \operatorname{Pr} \zeta^{5}-45 \mathrm{Ec} \operatorname{Pr} \zeta^{7}\right) \\
+\frac{1}{725760}\left(\begin{array}{l}
19 \mathrm{Ec} \operatorname{Pr} \delta-35 \mathrm{Ec} \operatorname{Pr} \delta \zeta^{2}+70 \mathrm{Ec} \operatorname{Pr} \delta \zeta^{4}-126 \mathrm{Ec} \operatorname{Pr} \delta \zeta^{6} \\
+135 \mathrm{Ec} \operatorname{Pr} \delta \zeta^{8}-63 \mathrm{Ec} \operatorname{Pr} \delta \zeta^{10}
\end{array}\right)
\end{gathered}
$$

\section{Method of solution: Daftardar-Gejiji \& Jafari Method (DJM)}

The procedure of the Daftardar-Gejiji \& Jafari method (DJM) is given as follows: Consider the following equation

$$
u(\bar{x})=f(\bar{x})+N(u(\bar{x}))
$$

where $N$ is a nonlinear operator from a Banach space $\boldsymbol{B} \rightarrow \boldsymbol{B}$ and $f$ is a known function $\bar{x}=\left(x_{1}, x_{2}, \ldots x_{n}\right)$. The solution $u$ in Eq. (36) have a form of series solution as

$$
u(\bar{x})=\sum_{n=0}^{\infty}(\bar{x})
$$

The nonlinear operator $N$ can be decomposed as

$$
N\left(\sum_{n=0}^{\infty} u_{i}\right)=N\left(u_{0}\right)+\sum_{i=0}^{\infty}\left\{N\left(\sum_{j=0}^{i} u_{j}\right)-N\left(\sum_{j=0}^{i-1} u_{j}\right)\right\}
$$


From equations (37) and (38), equation (36) is equivalent to

$$
\sum_{n=0}^{\infty} u_{i}=f+N\left(u_{0}\right)+\sum_{i=0}^{\infty}\left\{N\left(\sum_{j=0}^{i} u_{j}\right)-N\left(\sum_{j=0}^{i-1} u_{j}\right)\right\}
$$

Hence, the solution to the governing equation (9), (10) and boundary conditions (12), are given by the recurrence relation

$$
u_{0}=a+b \zeta, \theta_{0}=c+d \zeta
$$

And the DJM establishes that the step by step solution of any function is obtained in the form;

$$
\begin{gathered}
f_{2}=f\left(N_{0}+N_{1}\right)-f\left(N_{0}\right) \\
f_{3}=f\left(N_{0}+N_{1}+N_{2}\right)-f\left(N_{0}+N_{1}\right) \\
f_{4}=f\left(N_{0}+N_{1}+N_{2}+N_{4}\right)-f\left(N_{0}+N_{1}+N_{2}\right) \\
f_{5}=f\left(N_{0}+N_{1}+N_{2}+N_{4}+N_{5}\right)-f\left(N_{0}+N_{1}+N_{2}+N_{4}\right)
\end{gathered}
$$

So, the momentum equation becomes

$$
\begin{gathered}
u_{1}=-\int_{0}^{\zeta} \int_{0}^{\zeta}\left(6 \delta\left(\frac{\mathrm{d}}{\mathrm{d} \zeta} u_{0}\right)^{2} \frac{\mathrm{d}^{2}}{\mathrm{~d} \zeta^{2}} u_{0}+\theta_{0}\right) d \zeta d \zeta \\
u_{2}=-\int_{0}^{\zeta} \int_{0}^{\zeta}\left(6 \delta\left(\frac{\mathrm{d}}{\mathrm{d} \zeta}\left(u_{0}+u_{1}\right)\right)^{2} \frac{\mathrm{d}^{2}}{\mathrm{~d} \zeta^{2}}\left(u_{0}+u_{1}\right)+\left(\theta_{0}+\theta_{1}\right)\right) d \zeta d \zeta \\
-\left(-\int_{0}^{\zeta} \int_{0}^{\zeta}\left(6 \delta\left(\frac{\mathrm{d}}{\mathrm{d} \zeta} u_{0}\right)^{2} \frac{\mathrm{d}^{2}}{\mathrm{~d} \zeta^{2}} u_{0}+\theta_{0}\right) d \zeta d \zeta\right) \\
u_{3}=-\int_{0}^{\zeta} \int_{0}^{\zeta}\left(6 \delta\left(\frac{\mathrm{d}}{\mathrm{d} \zeta}\left(u_{0}+u_{1}+u_{2}\right)\right)^{2} \frac{\mathrm{d}^{2}}{\mathrm{~d} \zeta^{2}}\left(u_{0}+u_{1}+u_{2}\right)+\left(\theta_{0}+\theta_{1}+\theta_{2}\right)\right) d \zeta d \zeta \\
-\left(-\int_{0}^{\zeta} \int_{0}^{\zeta}\left(6 \delta\left(\frac{\mathrm{d}}{\mathrm{d} \zeta}\left(u_{0}+u_{1}\right)\right)^{2} \frac{\mathrm{d}^{2}}{\mathrm{~d} \zeta^{2}}\left(u_{0}+u_{1}\right)+\left(\theta_{0}+\theta_{1}\right)\right) d \zeta d \zeta\right)
\end{gathered}
$$

And the energy equation becomes 


$$
\begin{gathered}
\theta_{1}=-\int_{0}^{\zeta} \int_{0}^{\zeta}\left(\operatorname{EcPr}\left(\frac{\mathrm{d}}{\mathrm{d} \zeta} u_{0}\right)^{2} \frac{\mathrm{d}^{2}}{\mathrm{~d} \zeta^{2}} u_{0}+2 \delta \operatorname{EcPr}\left(\frac{\mathrm{d}}{\mathrm{d} \zeta} u_{0}\right)^{4}\right) d \zeta d \zeta \\
\theta_{2}=-\int_{0}^{\zeta} \int_{0}^{\zeta}\left(\operatorname{Ec} \operatorname{Pr}\left(\frac{\mathrm{d}}{\mathrm{d} \zeta}\left(u_{0}+u_{1}\right)\right)^{2} \frac{\mathrm{d}^{2}}{\mathrm{~d} \zeta^{2}}\left(u_{0}+u_{1}\right)+2 \delta \operatorname{Ec} \operatorname{Pr}\left(\frac{\mathrm{d}}{\mathrm{d} \zeta}\left(u_{0}+u_{1}\right)\right)^{4}\right) d \zeta d \zeta \\
-\left(-\int_{0}^{\zeta} \int_{0}^{\zeta}\left(\operatorname{Ec} \operatorname{Pr}\left(\frac{\mathrm{d}}{\mathrm{d} \zeta} u_{0}\right)^{2} \frac{\mathrm{d}^{2}}{\mathrm{~d} \zeta^{2}} u_{0}+2 \delta \operatorname{Ec} \operatorname{Pr}\left(\frac{\mathrm{d}}{\mathrm{d} \zeta} u_{0}\right)^{4}\right) d \zeta d \zeta\right) \\
\theta_{3}=-\int_{0}^{\zeta} \int_{0}^{\zeta}\left(\operatorname{Ec} \operatorname{Pr}\left(\frac{\mathrm{d}}{\mathrm{d} \zeta}\left(u_{0}+u_{1}+u_{1}\right)\right)^{2} \frac{\mathrm{d}^{2}}{\mathrm{~d} \zeta^{2}}\left(u_{0}+u_{1}+u_{1}\right)+2 \delta \operatorname{EcPr}\left(\frac{\mathrm{d}}{\mathrm{d} \zeta}\left(u_{0}+u_{1}+u_{1}\right)\right)^{4}\right) d \zeta d \zeta \\
-\left(-\int_{0}^{\zeta} \int_{0}^{\zeta}\left(\operatorname{EcPr}\left(\frac{\mathrm{d}}{\mathrm{d} \zeta}\left(u_{0}+u_{1}\right)\right)^{2} \frac{\mathrm{d}^{2}}{\mathrm{~d} \zeta^{2}}\left(u_{0}+u_{1}\right)+2 \delta \operatorname{Ec} \operatorname{Pr}\left(\frac{\mathrm{d}}{\mathrm{d} \zeta}\left(u_{0}+u_{1}\right)\right)^{4}\right) d \zeta d \zeta\right)
\end{gathered}
$$

Hence,

$$
\begin{gathered}
u_{1}=-\frac{1}{6} d \zeta^{3}-\frac{1}{2} c \zeta^{2} \\
u_{2}=\left(\begin{array}{l}
\frac{1}{28} \delta d^{3} \zeta^{7}+\frac{1}{4} \delta c d^{2} \zeta^{6}+\frac{1}{5}\left(\frac{3}{2} \delta\left(-b d+c^{2}\right) d+\frac{3}{2} \delta c^{2} d\right) \zeta^{5} \\
+\frac{1}{4}\left(-4 \delta b c d+2 \delta\left(-b d+c^{2}\right) c+\frac{1}{3} \operatorname{EcPr} b^{4} \delta\right) \zeta^{4}+\frac{1}{3}\left(3 \delta b^{2} d-6 \delta b c^{2}-\frac{d}{2}\right) \zeta^{3}+ \\
\frac{1}{2}\left(6 b^{2} c \delta-c\right) \zeta^{2}
\end{array}\right)
\end{gathered}
$$

$$
\theta_{1}=-\delta \operatorname{Ec} \operatorname{Pr} b^{4} \zeta^{2}
$$


$\theta_{2}=\left(\begin{array}{l}-\frac{\delta \mathrm{Ec} \operatorname{Pr} d^{4} \zeta^{10}}{720}-\frac{\delta \mathrm{Ec} \operatorname{Pr} c d^{3} \zeta^{9}}{72}-\frac{1}{28} \delta \mathrm{Ec} \operatorname{Pr}\left(\frac{1}{2}\left(-b d+c^{2}\right) d^{2}+c^{2} d^{2}\right) \zeta^{8} \\ +\frac{1}{7}\left(\frac{1}{24} \mathrm{Ec} \operatorname{Pr} d^{3}-\frac{1}{3} \delta \mathrm{Ec} \operatorname{Pr}\left(-b c d^{2}+2\left(-b d+c^{2}\right) c d\right)\right) \zeta^{7} \\ +\frac{1}{6}\left(\frac{1}{4} \mathrm{Ec} \operatorname{Pr} c d^{2}-\frac{2}{5} \delta \mathrm{Ec} \operatorname{Pr}\left(\frac{1}{2} b^{2} d^{2}-4 b c^{2} d+\left(-b d+c^{2}\right)^{2}\right)\right) \zeta^{6} \\ +\frac{1}{5}\left(\frac{1}{4} \mathrm{Ec} \operatorname{Pr}\left(-b d+c^{2}\right) d+\frac{1}{4} \mathrm{Ec} \operatorname{Pr} c^{2} d-\frac{1}{2} \delta \mathrm{Ec} \operatorname{Pr}\left(2 b^{2} c d-4 b c\left(-b d+c^{2}\right)\right)\right) \zeta^{5} \\ +\frac{1}{4}\left(-\frac{2}{3} \mathrm{Ec} \operatorname{Pr} b c d+\frac{1}{3} \mathrm{Ec} \operatorname{Pr}\left(-b d+c^{2}\right) c-\frac{2}{3} \delta \mathrm{Ec} \operatorname{Pr}\left(2 b^{2}\left(-b d+c^{2}\right)+4 b^{2} c^{2}\right)\right) \zeta^{4} \\ +\frac{1}{3}\left(4 \delta \mathrm{Ec} \operatorname{Pr} b^{3} c+\frac{1}{2} \mathrm{Ec} \operatorname{Pr} b^{2} d-\operatorname{Ec} \operatorname{Pr} b c^{2}\right) \zeta^{3}-\operatorname{Ec} \operatorname{Pr} b^{4} \delta+\frac{1}{2} \mathrm{Ec} \operatorname{Pr} b^{2} c\end{array}\right)$

For $\operatorname{Pr}=\mathrm{Ec}=\delta=1$, the values of the constants becomes: $a=0.24112 \cdot 10^{-4}$, $b=-0.83335 \cdot 10^{-1}, c=0.48238 \cdot 10^{-4}, d=-0.500000$.

\section{Results and discussion}

In this study, the heat transfer analysis of natural convective non-Newtonian fluid flow between two vertically infinite parallel plates has been investigated for velocity and temperature profiles. The governing equation, which is a pair of coupled nonlinear ordinary differential equation was solved analytically by using the homotopy perturbation method (HPM) and Daftardar-Gejiji \& Jafari Method (DJM). The results are validated by a numerical solution done with the "Numerical Solution of Differential Equations" package "NDSolveValue" in Mathematica 10.0. and presented in Table 1 . The error analysis carried out showed that an accepted error of less than 3\% was observed in the differences of the solutions between the results obtained from the homotopy perturbation method, the Daftardar-Gejiji \& Jafari Method (DJM) and the numerical method for both velocity and temperature profiles. The homotopy perturbation method can be an efficient tool for predicting the profiles of nonlinear heat transfer of natural convection of non-Newtonian fluid between two infinite flat plate.

The effects of different parameters such as the Eckert number Ec, the Prandtl number Pr and the non-Newtonian fluid viscosity parameter $\delta$ are demonstrated in the figures which follow. In Figures $2 a$ and $2 b$, the effects of the Eckert number Ec on fluid velocity and temperature are investigated and the results are presented. It is observed that the fluid velocity exhibits a delayed flow profile around the plate region while the temperature decreases significantly with increasing Ec. Further- 
more, the results show that the Ec number has minimal effect on the fluid velocity and temperature variations. Figures $3 \mathrm{a}$ and $3 \mathrm{~b}$ show the results of non-dimensional fluid velocity and temperature for various Prandtl number Pr, and the effect of Pr is investigated. Similar results as observed in the effect of Ec number (Fig. 2a and 2b) are also observed for Pr. The same results were obtained by Ahmed et al. [20].

Table 1. Comparison of HPM, DJM and numerical method results

\begin{tabular}{|c|c|c|c|c|c|}
\hline \multicolumn{7}{|c|}{ The results of HPM, DJM and Numerical methods for $u(\xi)$ for } \\
\hline$\xi$ & HPM & DJM $=1$, Ec $=1, \delta=1$ & NUM & Error of HPM & Error of DJM \\
\hline-1.00 & 0.000000 & 0.00000 & 0.00000 & 0.000000 & 0.000000 \\
\hline-0.80 & 0.023309 & 0.02331 & 0.02337 & -0.000061 & -0.000060 \\
\hline-0.60 & 0.031366 & 0.03142 & 0.03142 & -0.000054 & 0.000000 \\
\hline-0.40 & 0.027481 & 0.02753 & 0.02753 & -0.000049 & 0.000000 \\
\hline-0.20 & 0.015682 & 0.01571 & 0.01571 & -0.000028 & 0.000000 \\
\hline 0.00 & 0.000000 & 0.00001 & 0.00001 & -0.000010 & 0.000000 \\
\hline 0.20 & -0.015682 & -0.01570 & -0.01570 & 0.000018 & 0.000000 \\
\hline 0.40 & -0.027481 & -0.02751 & -0.02751 & 0.000029 & 0.000000 \\
\hline 0.60 & -0.031366 & -0.03141 & -0.03141 & 0.000044 & 0.000000 \\
\hline 0.80 & -0.023309 & -0.02337 & -0.02337 & 0.000061 & 0.000000 \\
\hline 1.00 & 0.000000 & 0.00000 & 0.00000 & 0.000000 & 0.000000 \\
\hline
\end{tabular}

In Figures $4 \mathrm{a}$ and $4 \mathrm{~b}$, the effects of the non-Newtonian fluid viscosity parameter $\delta$ on temperature and fluid velocity are investigated and presented. These figures show that $\delta$ has no effect on the varying temperatures but the fluid velocity decreases significantly. This same observation was made by Hatami and Ganji [3].
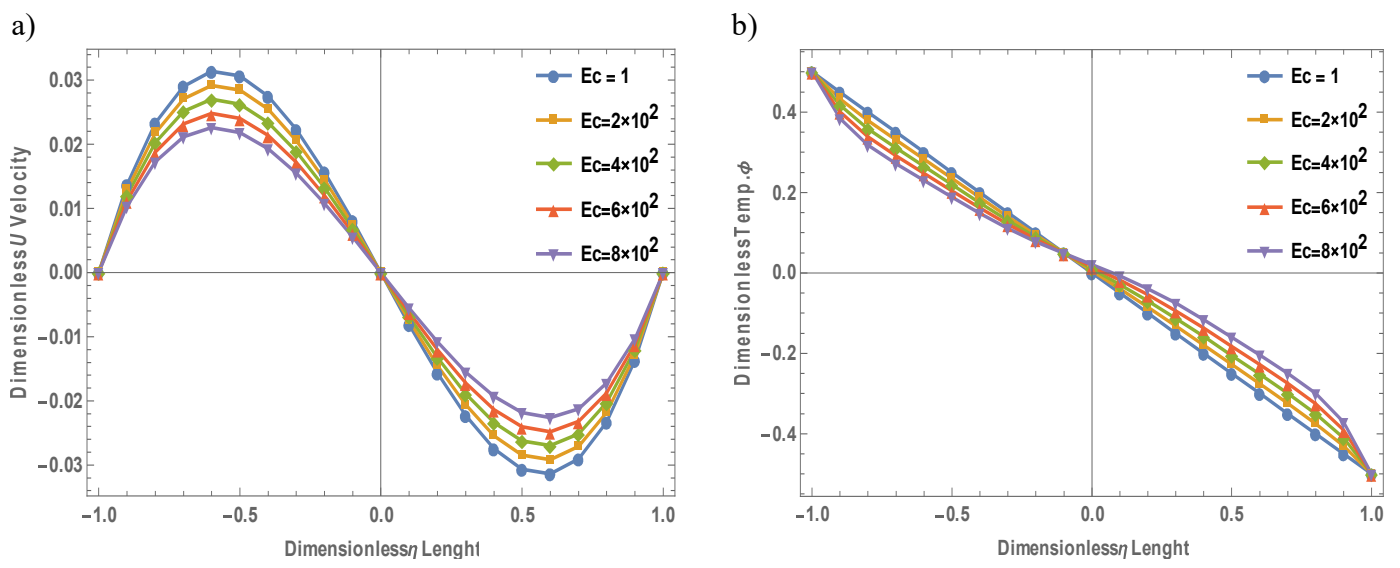

Fig. 2. The fluid velocity $U(\xi)$ (a) and temperature $\varphi(\xi)$ (b) for various $\operatorname{Ec}$ at $\operatorname{Pr}=\delta=1$ 

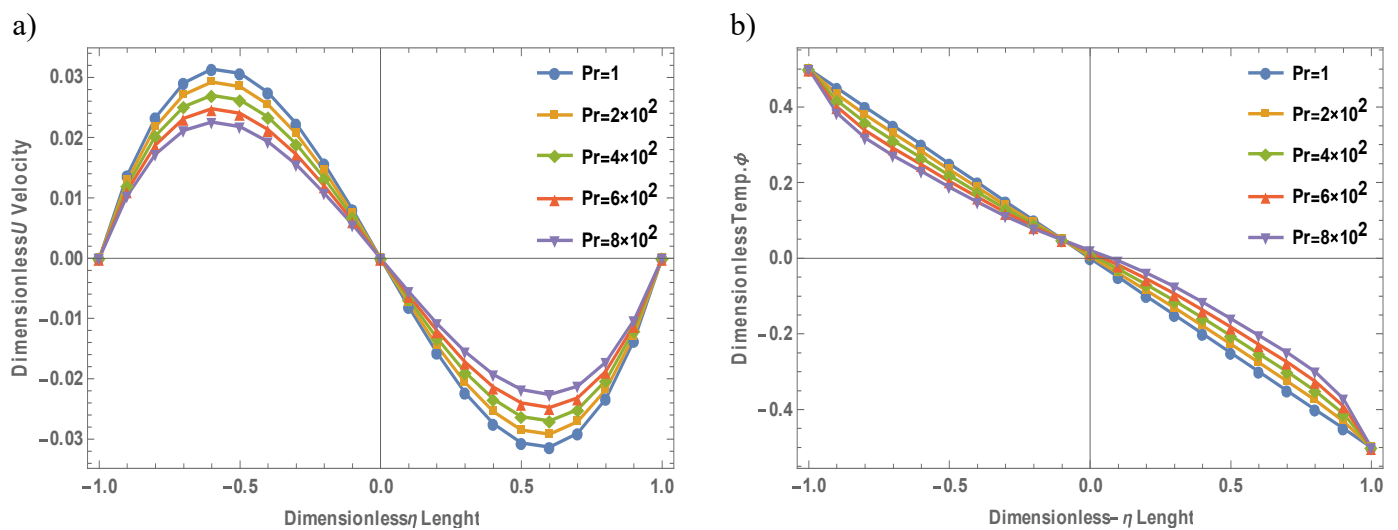

Fig. 3. The fluid velocity $U(\xi)$ (a) and temperature $\varphi(\xi)$ (b) for various $\operatorname{Pr}$ at $\mathrm{Ec}=\delta=1$

a)

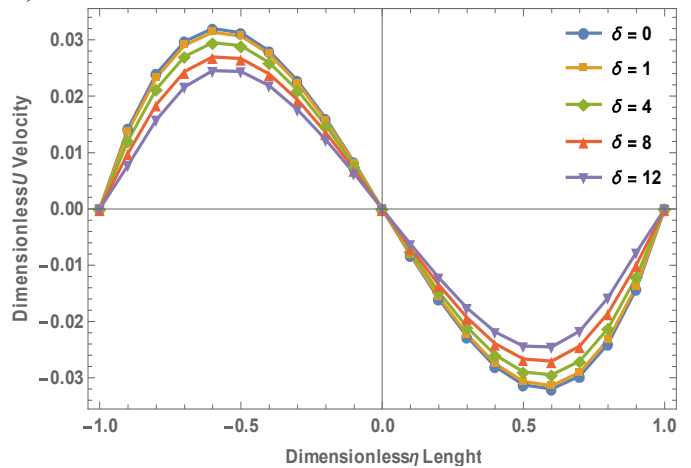

b)

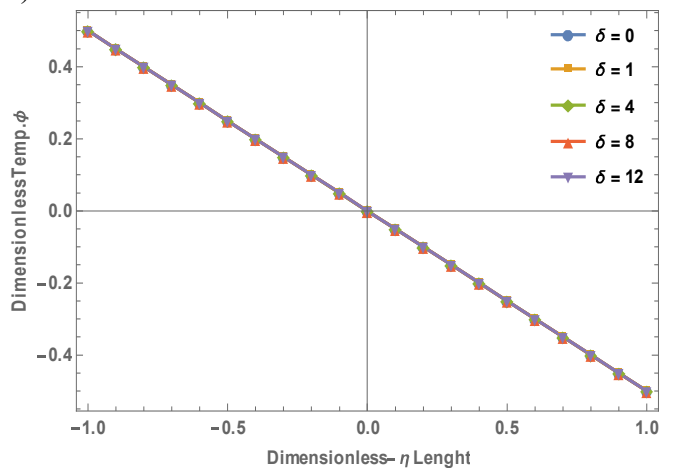

Fig. 4. The fluid velocity $U(\xi)$ (a) and temperature $\varphi(\xi)$ (b) for various $\delta$ at $\operatorname{Ec}=\operatorname{Pr}=1$

\section{Conclusions}

In this study, we have applied the homotopy perturbation method and the Daftardar-Gejiji \& Jafari Method (DJM) to obtain an analytical solution to the problem of heat transfer on non-Newtonian natural convective fluid flow between two vertically infinite parallel plates. The analytical solutions were validated by the numerical method, and an excellent agreement was observed between the methods of solution so the homotopy perturbation method and the Daftardar-Gejiji \& Jafari Method (DJM) is very useful in obtaining analytical solutions to problems in engineering, science and other areas of application. The effects of the Eckert number, the Prandtl number and the non-Newtonian fluid viscosity parameter on temperature and velocity were investigated. Hence, it can be concluded that by increasing the Eckert number and the Prandtl number, there will be an increase in both temperature and fluid flow velocity. 


\section{Nomenclature}

$\begin{array}{ll}\mathbf{\tau} & \text { stress tensor } \\ \mathbf{\rho} & \text { constant fluid density } \\ \mathbf{f b} & \text { body force } \\ \mathbf{T} & \text { temperature } \\ \mathbf{K} & \text { thermal conductivity } \\ \mathbf{V} & \text { velocity field } \\ \mathbf{c}_{\mathbf{p}} & \text { specific heat at constant pressure } \\ \mathbf{L} & \text { gradient of velocity field } \\ \boldsymbol{p} & \text { pressure } \\ \mu & \text { coefficient of viscosity } \\ \alpha_{1} & \text { material constants } \\ \mathbf{A}_{1} & \text { Erickson tensors } \\ \text { Ec } & \text { Eckert number } \\ \operatorname{Pr} & \text { Prandtl number } \\ \delta & \text { non-Newtonian viscosity } \\ U(\xi) & \text { non-dimensional velocity field } \\ \varphi(\xi) & \text { non-dimensional temperature field } \\ \xi & \text { non-dimensionlal x cordinate }\end{array}$

\section{References}

[1] Cheng, C. (2009). Natural convection heat transfer of non-Newtonian fluids in porous media from a vertical cone under mixed thermal boundary conditions. International Communications in Heat and Mass Transfer, 36, 693-697.

[2] Pourmehran, O., Rahimi-Gorji, M., Tavana, M., Gorji-Bandpy, M., \& Ganji, D.D. (2017). Heat transfer investigation of non-Newtonian fluid between two vertically infinite flat plates by numerical and analytical solutions. Heighpubs Biomed Sci. Eng. 1, 001-011.

[3] Hatami, M., \& Ganji, D.D. (2014). Natural Convection of Sodium Alginate (SA) Non-Newtonian Nanofluid Flow between Two Vertical Flat Plates by Analytical and Numerical Methods. Case Studies in Thermal Engineering, Elsevier, Vol. 2, 14-22.

[4] Ghadikolaei, S.S., Hosseinzadeh, Kh., Yassari, M., Sadeghi, H., \& Ganji, D.D. (2018). Analytical and numerical solution of non-Newtonian second-grade fluid flow on a stretching sheet. Thermal Science and Engineering Progress, 5, 309-316.

[5] Hatami, M., Hatami, J., \& Ganji, D.D. (2014). Computer simulation of MHD blood conveying gold nanoparticles as a third grade non-Newtonian nanofluid in a hollow porous vessel. Computer Methods and Programs in Medicine, 113, 632-641.

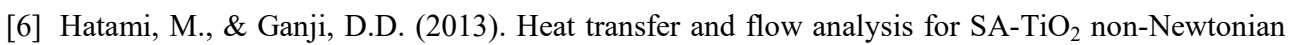
nanofluid passing through the porous media between two coaxial cylinders. Journal of Molecular Liquids, 188, 155-161.

[7] Gorla, R.S., \& Bakier, A.Y. (2011). Thermal analysis of natural convection and radiation in porous fins. Int. Commun. Heat Mass Transfer, 38, 638-645.

[8] Rahbari, A., Fakour, M., Hamzehnezhad, A., Akbari, Vakilabadi, M., \& Ganji, D.D. (2017). Heat transfer and fluid flow of blood with nanoparticles through porous vessels in a magnetic field: A quasi-one dimensional analytical approach. Mathematical Biosciences, 283, 38-47. 
[9] Darvishi, M.T., Gorla, R.S.R., Khani, R.S., Khani, F., \& Aziz, A.E. (2015). Thermal performance of a porus radial fin with natural convection and radiative heat losses. Therm. Sci., 19(2), 669-678.

[10] Hayat, T., Ellahi, R., \& Mahomed, F.M. (2008). Exact solutions for thin film flow of a third grade fluid down an inclined plane. Chaos Solitons Fractals, 38(5), 1336-1341.

[11] Ellahi, R., \& Riaz, A. (2010). Analytical solutions for MHD flow in a third-grade fluid with variable viscosity. Math. Comput. Model., 52, 1783-1793.

[12] Murthy, P.S.V.N., \& Singh, P. (1997). Thermal dispersion effects on non-Darcy natural convection over horizontal plate with surface mass flux. Archive of Applied Mechanics, 67, 487-495.

[13] Magyari, E., \& Keller, B. (2000). Exact solutions for self-similar boundary-layer flows induced by permeable stretching walls. European Journal of Mechanics B-Fluids, 19, 109-122.

[14] Mohyud-Din, S.T. (2010). Variational iteration method for Hirota-Satsuma Model using He's polynomials. Zeitschriftfür Naturforschung A-A Journal of Physical Sciences, 65(6-7), 525-528.

[15] Domairry, D., Sheikholeslami, M., Ashorynejad, H.R., Reddy, R.S., \& Gorla, K.M. (2012). Natural convection flow of a non-Newtonian nanofluid between two vertical flat plates. Proceedings of the Institution of Mechanical, Part N: Journal Nanoengineering and Nanosystems, 225(3), 115-122.

[16] Hasanpour, A., Parvizi Omran, M., Ashorynejad, H.R., Ganji, D.D., Kadhim Hussein, A., \& Moheimani, R. (2011). Investigation of heat and mass transfer of MHD flow over the movable permeable plumb surface using HAM. Middle-East Journal of Scientific Research, 9(4), 510-515.

[17] Sheikholeslami, M., Ganji, D.D., Ashorynejad, H.R., \& Ronki, H.B. (2012). Analytical investigation of Jeffery-Hamel flow with high magnetic field and nanoparticle by Adomian decomposition method. Applied Mathematics and Mechanics - English Edition, 33(1), 25-36.

[18] Saedodin, S., \& Shahbabaei, M. (2013). Thermal analysis of natural convection in porous fins with homotopy perturbation method (HPM). Arab. J. Sci. Eng., 38, 2227-2231.

[19] Hoshyar, H.A., Rahimipetroudi, I., Ganji, D.D., \& Majidian, A.R. (2015). Thermal performance of porous fins with temperature-dependent heat generation via Homotopy perturbation method and collocation method. J. Appl. Math. Computat. Mech., 14(4), 53-65.

[20] Sheikholeslami, M., Ashorynejad, H.R., Ganji, D.D., \& Yildirim, A. (2012). Homotopy perturbation method for three dimensional problem of condensation film on inclined rotating disk, Scientia Iranica B, 19(3), 437-442.

[21] Zhou, J.K. (1986). Differential Transformation and Its Applications for Electrical Circuits. Wuhan: Huazhong University Press (in Chinese).

[22] Daftardar-Gejji, V., \& Bhalekar, S. (2008). An iterative method for solving fractional differential equations. Proc. Appl. Math. Mech., 7, 2050017-18.

[23] Jafari, H., Seifi, S., Alipoor, A., \& Zabihi, M. (2009). An iterative method for solving linear and nonlinear fractional diffusion-wave equation. Int. e-J Numer Anal. Relat. Topics, 3, 20-32.

[24] Ahmed, N., Jan, S.U., Khan, U., \& Mohyud-Din, S.T., (2015). Heat transfer analysis of thirdgrade fluid flow between parallel plates: Analytical solution. Int. J. Appl. Comput. Math.

[25] Rajagopal, K.R., \& Ty, N. (1985). Natural convection flow of a non-Newtonian fluid between two vertical flat plates. Acta Mech., 54, 239-246. 